\title{
Synthesis and Characterization of Transition Metal Complexes of Para-Aminosalicylic Acid With Evaluation of Their Antioxidant Activities
}

\author{
ABDUL BASIT WANI ${ }^{1 *}$, JOGINDER SINGH ${ }^{2}$ and NIRAJ UPADHYAY ${ }^{3}$ \\ 1'Department of Chemistry, Lovely Professional University, Punjab, India. \\ ${ }^{2}$ Department of Biotechnology, Lovely Professional University, Punjab, India. \\ ${ }^{3}$ Department of Chemistry, Dr. Hari Singh Gour University, Madhya Pradesh, India. \\ ${ }^{*}$ Corresponding author E-mail: wanibasit.chem @ gmail.com \\ http://dx.doi.org/10.13005/ojc/330308
}

(Received: April 24, 2017; Accepted: May 20, 2017)

\begin{abstract}
Complexing behavior of Para-aminosalicylic acid (PAS) towards Mn(II), Fe(II), Co(II), Ni(II), $\mathrm{Cu}(\mathrm{ii}), \mathrm{Zn}(\mathrm{II})$, have been examined by Conductance and magnetic measurements and by UVvisible, IR and ${ }^{1} \mathrm{H}$ NMR. Thermal decomposition properties of the complexes are investigated by thermogravimetric analysis (TGA). The free ligand and its complexes were tested for antioxidant activity and evaluation of $I C_{50}$ values. It was found that PAS and its all complexes have low $I C_{50}$ value than standard ascorbic acid. All complexes have lower $\mathrm{IC}_{50}$ value than PAS with $\mathrm{Ni}$ complex the least value. . Therefore, PAS and its complexes with these metal ions can act as antioxidants to reduce oxidative stresses.
\end{abstract}

Keywords: Para-aminosalicylic acid, metal complexes, thermal analysis, antioxidant activity, $\mathrm{IC}_{50}$

\section{INTRODUCTION}

4-amino-2-hydroxy-benzoic acid or 4-aminosalicylic acid commonly known as para-amino salicylic acid (PAS), an amine derivative of salicylic acid, is an antibiotic and one among the World Health Organization's List of Essential Medicines. PAS is a well-known antibacterial drug used in combination with first line drugs like isoniazid, rifampicin, etc'. Recently, PAS has been found effective in treatment of cancer and inflammatory bowel disease ${ }^{2}$. PAS also has modest activity against Influenza virus $A^{3,4}$. PAS is one of the first anti-tuberculosis agents found to be effective in $1940 s^{5}$. Today, PAS is used primarily as a second-line drug to treat multi drug resistanttuberculosis 6 . PAS, a bacteriostatic agent, is extremely helpful in controlling the growth of bacteria. It is also very useful in avoiding the development of the resistance of bacteria to the other anti-multi drug resistant -tuberculosis drugs ${ }^{7}$. 
Various studies have been carried out to examine the effectiveness of anti-inflammatory drugs as scavengers of reactive oxygen species (ROS), viz. superoxide radical (20*), hydrogen peroxide $\left(\mathrm{H}_{2} \mathrm{O}_{2}\right)$, hydroxyl $(\mathrm{HO})$, and hypochlorous acid $(\mathrm{HOCl})^{8}$. Halli well and Gutteridge (1985) have reported that non-steroidal anti-inflammatory drugs (NSAIDs) are powerful free radical scavengers ${ }^{9}$. Further, it is reported that NSAID, including analogs of salicylates, can exert neuroprotective effect by blocking inflammatory processes in neuro degenerative disease ${ }^{10}$. Therefore, PAS, being a salicylate analog, is expected to have the capacity of radical scavenging and hence can act as an antioxidant to reduce oxidative stress.

As a derivative of salicylic acid, PAS acts as a metal chelator ${ }^{11}$, is clinically effective drug for treatment of serious chronic manganese poisoning ${ }^{12,13}$. This chelating tendency of PAS can be exploited for the formation of essential metal complexes which are useful for having better biological activities especially antioxidant activities. Further, these metal complexes are gaining attention because of their diverse applications in almost all fields of life. More specifically the medicinal properties of essential metal ion chelates are fascinating ${ }^{14}$. There is also a need to explore the role of trace elements, essential elements or micronutrients (in their native or chelate forms) both in plants and animals and to explain their specific and extended roles at various stages ${ }^{15}$.

Considering these literature links, the complexation behavior of PAS with essential metal ions viz. Manganese (Mn), Iron (Fe), Cobalt (Co), Nickel (Ni), Copper ( $\mathrm{Cu}$ ) and Zinc ( $\mathrm{Zn})$ has been studied in vitro. The PAS and the prepared complexes were tested for antioxidant activities with 1,1-Diphenyl-2-picryl-hydrazyl (DPPH). Scavenging of DPPH radical is the basis of the popular DPPH antioxidant assay. Therefore, rate of reduction of a chemical reaction upon addition of DPPH is used as an indicator of the radical nature of that reaction ${ }^{16}$. The antioxidant activities obtained in this manner were then compared with a positive control, Vitamin $\mathrm{C} /$ Ascorbic acid (AA). AA is regarded as the most important water-soluble micronutrient in human plasma and mammalian cells, required for multiple biological functions. In biological systems, AA is an effective reducing agent and free radical scavenger, in addition to its antiscorbutic action ${ }^{17}$. The antioxidant activity was calculated on the basis of its radical scavenging activity (RSA) (percentage of inhibition) and $\mathrm{IC}_{50}$ (total antioxidant necessary to decrease the initial DPPH radical by $50 \%$ ) values.

\section{MATERIALS AND METHODS}

\section{Synthesis of metal complexes}

All chemicals used were of analytical reagent grade (AR), and of highest purity available. Synthesis was carried out by the procedure as used by Soliman and Mohamed (2013) with minor alteration. The metal complexes were prepared by the addition of aqueous solution of the appropriate metal acetates to the methanolic solution of SA in 1: 2 ratio. The resulting mixture was stirred for $3 \mathrm{~h}$ at room temperature and simultaneously checked for the reaction progress. The complexes were collected after slow evaporation of the solvent, then washed with methanol and air dried ${ }^{18}$.

\section{Instruments}

Melting points were calculated on $\mathrm{BUCH}$ melting point B-545 and molar conductance of solid chelates in methanol were measured using conductometer (Labtronics-Model LT-16). Infrared spectra were recorded on Shimadzu FT-IR type FTIR$8400 S$ spectrometer. Electronic transitions, reaction progress and antioxidant activity were measured on Shimadzu UV Probe Version 2.33 spectrophotometer. The molar magnetic susceptibility was measured on powdered samples using the Faraday method. The diamagnetic corrections were made by Pascal's constant and $\mathrm{Hg}\left[\mathrm{Co}(\mathrm{SCN})_{4}\right]$ was used as a calibrant. The $1 \mathrm{H}$ NMR spectra were recorded using Bruker Avence II 400 NMR spectrometer at SAIF PU Chandigarh. Thermo gravimetric analysis was carried out at STIC Cochin, Kochi at a heating rate of $20^{\circ} \mathrm{C} / \mathrm{min}$.

\section{Antioxidant activity}

The antioxidant activity in terms of free radical scavenging activity (RSA) of PAS and its complexes were measured by using 1, 1- diphenyl2-picrilhydrazyl (DPPH) assay. 20, 40, 60, 80, 100 $\mathrm{L}$ of $100 \mathrm{ppm}$ ethanolic solution of each compound were mixed with $4 \mathrm{~mL}$ of $0.1 \mathrm{mM}$ ethanolic solution of DPPH. The mixture was shaken vigorously and left to 
stand for 30 minutes in the dark. The absorbance was then measured at $517 \mathrm{~nm}$ against a blank. The control was prepared, as above, without any complex added and ethanol was used for the base line correction. AA was used as the reference (positive control) with the same concentrations as of PAS and its complexes. RSA was expressed as percentage inhibition and calculated as:

RSA = (Absorption of control " Absorption of sample) / Absorption of control x $100^{19}$.

IC50 values were calculated from the regression of the plotted graph of RSC against the concentrations of the samples ${ }^{20}$.

\section{RESULTS AND DISCUSSION}

The binary transition metal complex formation with PAS with the evaluation of radical scavenging activity in terms of $\mathrm{IC}_{50}$ have been studied first time, and may be an area of interest because these complexes may affect the bio availability of PAS as these metal ions are present in relatively appreciable concentration in biological fluids ${ }^{21}$.

\section{Molar conductance measurements}

Metal chelates are dissolved in methanol and the molar conductivity of $10^{-3} \mathrm{M}$ solutions is measured at room temperature. Table 1shows the molar conductance values of the complexes which are located in the range of non-electrolytes ${ }^{22}$ for all the complexes.

\section{Magnetic moment and Electronic spectral studies}

The room temperature magnetic moments of the complexes are in agreement with the spin free values (Table 1). The magnetic moment values for $\mathrm{Mn}(\mathrm{II}), \mathrm{Fe}(\mathrm{II}), \mathrm{Co}(\mathrm{II}), \mathrm{Ni}(\mathrm{II})$ and $\mathrm{Cu}(\mathrm{II})$ complexes indicate the high spin octahedral nature of these complexes.

The geometry of the metal complexes has been assumed from magnetic moment data and the electronic spectra of the complexes. The electronic spectra of the ligand, recorded by UV visible spectroscopy, show three bands at 208 , 262 and 293nm (Table 1) which are attributed to the benzene ring $\pi \rightarrow \pi^{*}$ transitions and to the chromophoresn $\rightarrow \pi^{\star}$ transitions, respectively. These bands were shifted in the electronic spectra of the complexes to 214-239, 261-184 and 290-315 nm, respectively ${ }^{23}$.

The UV spectrum Ni(II) complex shows two bands at 590 and 560nm which may be assigned to ${ }^{3} \mathrm{~A}_{2 g}(\mathrm{~F}) \rightarrow{ }^{3} \mathrm{~T}_{2 \mathrm{~g}}(\mathrm{~F})$ and ${ }^{3} \mathrm{~A}_{2 \mathrm{~g}}(\mathrm{~F}) \rightarrow{ }^{3} \mathrm{~T}_{1 \mathrm{~g}}(\mathrm{~F})$ transitions, thereby suggesting octahedral geometry of $\mathrm{Ni}(\mathrm{II})$ complex ${ }^{23} 22$. UV spectrum of the $\mathrm{Cu}$ (II) complex shows a band at $718 \mathrm{~nm}$, suggesting the existence of ${ }^{2} \mathrm{E}_{\mathrm{g}} \rightarrow{ }^{2} \mathrm{~T}_{1 \mathrm{~g}}$ transition which is consistent with an octahedral (more specifically distorted octahedral) configuration ${ }^{24}$.

\section{IR Analysis}

IR spectra is of great use in structural elucidation in absence of a powerful technique like single crystal XRD. The results of the IR measurements of PAS as well as metal complexes are tabulated in Table 2 (Fig. 1), wherein the assignments of the main bands (those affected by coordination) have been made. The sharp band at $3495 \mathrm{~cm}^{-1}$ is assigned to the phenoxy $\mathrm{O}-\mathrm{H}$ stretching vibration of PAS which disappears in metal complexes. Whereas, the sharp band at

Table 1: Physical data with electronic spectra of PAS and its metal complexes

\begin{tabular}{|c|c|c|c|c|c|c|c|c|}
\hline $\begin{array}{l}\text { Ligand/ } \\
\text { Complex }\end{array}$ & $\begin{array}{l}\text { Color } \\
\times \quad\end{array}$ & $\%$ Yield & $\begin{array}{l}\text { Melting } \\
\text { point } \\
\left({ }^{\circ} \mathrm{C}\right)\end{array}$ & $\begin{array}{c}\mu_{\mathrm{eff}} \\
\text { (B.M.) }\end{array}$ & $\begin{array}{c}\text { Molar } \\
\text { conductance } \\
\left(\mathrm{S} \cdot \mathrm{m}^{2} \cdot \mathrm{mol}^{-1}\right)\end{array}$ & $\begin{array}{c}\mathbf{n} \rightarrow \pi^{*} \\
(\mathrm{~nm})\end{array}$ & $\begin{array}{c}\pi \rightarrow \pi^{*} \\
(\mathbf{n m})\end{array}$ & $\begin{array}{c}d \rightarrow d \\
(\mathrm{~nm})\end{array}$ \\
\hline SA & Colorless & & $150 \pm 2$ & & & 293 & 262,208 & \\
\hline $\mathrm{Mn}(\mathrm{II})$ & Colorless & 80 & $225 \pm 2$ & 5.85 & 7.3491 & 310 & 262,214 & \\
\hline $\mathrm{Fe}(\mathrm{II}) \quad \mathrm{R} \epsilon$ & Reddish brown & 75 & $>285$ & 5.05 & 6.90288 & 301 & 261 & \\
\hline $\mathrm{Co}(\mathrm{II})$ & Magenta & 78 & $135 \pm 2$ & 5.01 & 9.28186 & 294 & 262,239 & \\
\hline $\mathrm{Ni}(\mathrm{II})$ & Light green & 80 & $>285$ & 2.90 & 4.86722 & 290 & 262,238 & 560,590 \\
\hline $\mathrm{Cu}(\mathrm{II})$ & Dark green & 76 & $>285$ & 1.75 & 4.92852 & 315 & 284 & 718 \\
\hline $\mathrm{Zn}(\mathrm{II})$ & white & 85 & $140 \pm 2$ & & 8.9688 & 294 & 276 & \\
\hline
\end{tabular}


$3387 \mathrm{~cm}^{-1}$ is assigned to the $\mathrm{N}-\mathrm{H}$ stretching vibration of $\mathrm{NH}_{2}$ group, which is broadened in complexes. The broadening of this band in complexes may be because of the attachment of water as ligand which is also confirmed from thermogravimetric analysis. The broadness may also be because of the presence of aromatic protons which absorb in the range of $3110-3200 \mathrm{~cm}^{-125}$. The characteristic absorption band at $1645 \mathrm{~cm}^{-1}$ was observed which can be attributed to asymmetric $v(\mathrm{COO})$ stretching vibration ${ }^{26}$, which in complexes faced red shift (bathochromic shift) with hypochromic effect, suggesting of weakening of $\mathrm{C}=\mathrm{O}$ bond and formation of $\mathrm{M}-\mathrm{O}$ bond.

Complexation is also suggested on behalf of red shift (bathochromic shift) with hypochromic effect in $\mathrm{C}-\mathrm{O}$ stretching vibrations of complexes to that of free ligand PAS $\left(1228 \mathrm{~cm}^{-1}\right)^{26}$. This suggests the weakening of $\mathrm{C}-\mathrm{O}$ bond and formation of stronger $\mathrm{M}-\mathrm{O}$ bond in complexes. In addition, bands in the region of $947-904 \mathrm{~cm}^{-1}$ and $825 \mathrm{~cm}^{-1}$ are assigned to the stretching vibrations of $\mathrm{M}-\mathrm{OH}_{2}$ bond ${ }^{18}$. The medium band at $970 \mathrm{~cm}^{-1}$ is assigned to out of plane bending $\gamma(\mathrm{OH})^{27}$, which was disappeared in complexes, indicates bonding through phenolic oxygen atom. Complexes also display week bands in the region $424-455 \mathrm{~cm}^{-1}$. These bands are assigned to $v(\mathrm{M}-\mathrm{O})$ stretching vibration. The week bands of 970 and $968 \mathrm{~cm}^{-1}$ in $\mathrm{Ni}(\mathrm{II})$ and $\mathrm{Cu}(\mathrm{II})$ complexes may be because of the out of plane $\gamma(\mathrm{CH})$ which becomes near degenerate with $\gamma(\mathrm{OH})$, whose intensity is very ${ }_{\text {Iow }}{ }^{27}$. Therefore, from the IR spectra it is concluded that PAS behaves as bidentate ligand with $\mathrm{OO}$ coordination sites and binds to the metal ions through carboxylate $\mathrm{O}$ and phenolic $\mathrm{O}$ atoms.

\section{${ }^{1} \mathrm{H}$ NMR Analysis}

${ }^{1} \mathrm{H}$ NMR spectra were carried out in DMSO$\mathrm{d}_{6}$ for the synthesized complex of $\mathrm{Zn}(\mathrm{II})$ and ligand PAS. Peak assignments are given in Table 3 for the corresponding protons and these are numbered in Fig. 2. Disappearance of the peak of phenolic

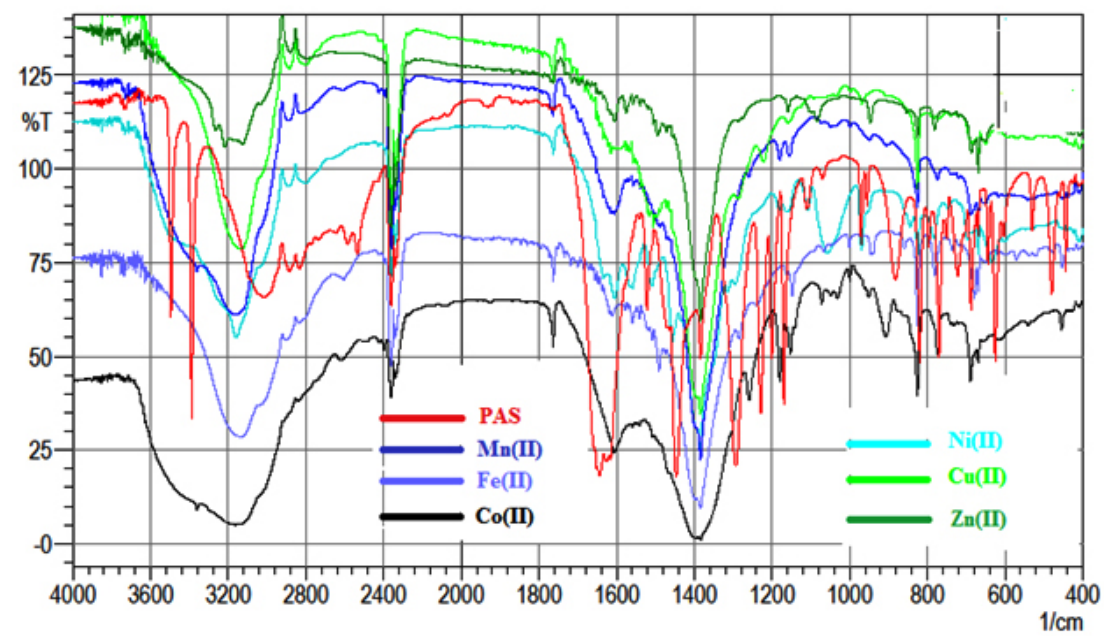

Fig. 1: IR plots of PAS and its metal complexes

Table 2: IR spectra of PAS and its metal complexes

\begin{tabular}{|c|c|c|c|c|c|c|c|}
\hline Complex/ Ligand & $v($ phe $)$ & $v(\mathbf{N H})$ & $v(\mathrm{COO})($ asym) & $v(\mathbf{C}-0)$ & \multicolumn{2}{|c|}{$\gamma(\mathrm{OH}) v(\mathbf{M}-\mathrm{O})\left(\mathbf{H}_{2} \mathrm{O}\right)$} & $v(\mathbf{M}-\mathbf{O})$ \\
\hline ASA & $3495 \mathrm{~s}$ & $3387 \mathrm{~s}$ & $1645 \mathrm{~s}$ & $1228 \mathrm{~s}$ & $970 \mathrm{~m}$ & & \\
\hline Mn(II) complex & & $3360 w$ & $1607 \mathrm{~b}$ & $1180 w$ & & 904 w, 825 m & $455 w$ \\
\hline $\mathrm{Fe}(\mathrm{II})$ complex & & & 1610 vs & $1227 w$ & & 939 vs, 825 s & $451 \mathrm{vs}$ \\
\hline Co(II) complex & & $3360 w$ & 1607 vs & $1180 \mathrm{~m}$ & & $906 \mathrm{~m}, 825 \mathrm{~s}$ & 451 vs \\
\hline $\mathrm{Ni}(\mathrm{II})$ complex & & & $1634 w$ & $1180 \mathrm{w}$ & 970 vs & $825 \mathrm{~m}$ & $453 w$ \\
\hline $\mathrm{Cu}(\mathrm{II})$ complex & & & $1614 \mathrm{w}$ & $1221 w$ & $968 w$ & 905 w, 825m & 455 vs \\
\hline Zn(II) complex & & $3265 \mathrm{w}$ & 1605 vs & $1205 \mathrm{w}$ & & 947 vs, $825 \mathrm{~m}$ & 424 vs \\
\hline
\end{tabular}


proton in the complexes indicate the involvement of the phenolic oxygen atom in complexation (Fig 3). A shift in the values of ring protons of complexes in comparison to the proton of PAS also suggests the complexation. No shift in the peak of $\mathrm{NH}$ protons in complex nullifies the bonding through $\mathrm{N}$ atom of $\mathrm{NH}_{2}$ group. So on the basis of analysis of the results obtained, it is concluded that the coordination of the PAS ligand to the metal ions occurs through the phenolic oxygen and carboxylic oxygen.

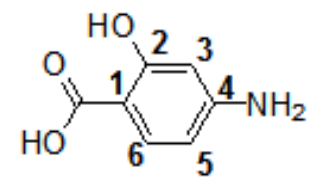

Fig. 2: Numbering pattern of carbon containing protons for ${ }^{1} \mathrm{H}$ NMR peak assignments
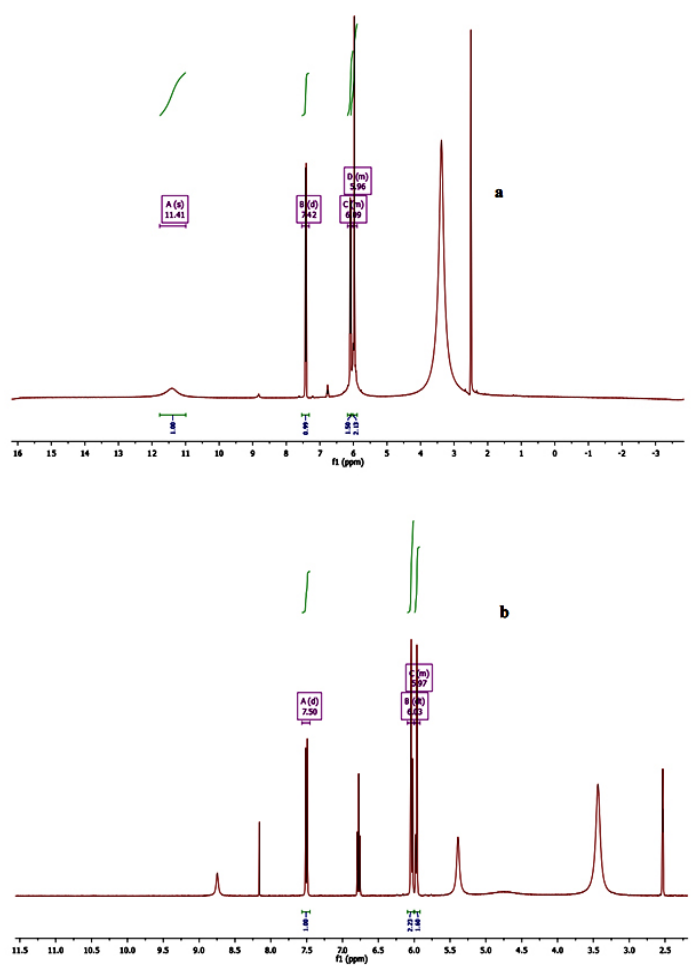

Fig. 3: ${ }^{1} \mathrm{H}$ NMR of a) PAS and b) Zn(II) complex of PAS

\section{Thermal analysis}

The complexes of PAS were also analyzed thermogravimetrically. The TG curves of complexes usually refers to three stages of mass losses within different temperature ranges. The first step of degradation corresponds to loss of coordinated water molecules which usually occurs in the range of $80-150^{\circ} \mathrm{C}$. Therefore coordinated water molecules are confirmed from TGA analysis. Next degradation steps followed similar degradation trends as is shown in Figure 4 for $\mathrm{Ni}(\mathrm{II})$ complex of PAS.

On the basis of said facts, the proposed structures for the metal complexes are shown in Fig. 5. It is suggested that the ligand and metal combine in 2:1 ratio and metal is coordinated via $O$ $\mathrm{O}$ atoms of the PAS to give octahedral geometry to the complexes.

\section{Antioxidant activity}

Antioxidant activity of PAS and all its metal complexes were evaluated in terms of DPPH radical scavenging activity (RSA) at 5 concentrations of $0,0.5,1.0,1.5$ and $2 \mu \mathrm{g} / \mathrm{mL}$ of the compound and corresponding $\mathrm{IC}_{50}$ values were obtained from their regression plot (Fig. 6). Ascorbic acid (AA) was used as a positive control. PAS and all its metal complexes show higher activity than the positive control, AA, with $I_{50}$ values $2.75 \mu \mathrm{g} / \mathrm{mL}$. The highest radical scavenging activity was observed for $\mathrm{Ni}$ (II) complex with $I_{50}$ value $0.88 \mu \mathrm{g} / \mathrm{mL}$ and for PAS it was lower than all the metal complexes with $\mathrm{IC}_{50}$ value $2.13 \mu \mathrm{g} / \mathrm{mL}$.

From the data of $I_{50}$ of $A A$, PAS and its metal complexes it is evident that all metal complexes are better antioxidants than PAS and standard AA. The higher antioxidant activity of metal complexes than PAS can be explained on some explanations cited in literature. It is reported by $R$ Milaeva $(2011)^{28}$ that the antioxidant activity of sterically hindered phenolic antioxidants is increased by metal complexation because: i) Of the modification in the chemical structures of metal complexes by changing metal or ligand nature; ii) of the stabilization

Table 3: Peak assignments of protons for ${ }^{1} \mathrm{H}$ NMR of PAS and its $\mathrm{Zn}$ (II) complex

\begin{tabular}{lccccc}
\hline Compound & $\delta(\mathbf{H} 3), \mathbf{p p m}$ & $\delta(\mathbf{H} 5), \mathbf{p p m}$ & $\delta(\mathbf{H} 6), \mathbf{p p m}$ & $\delta\left(\mathbf{H}_{\mathrm{NH}}\right)$ & $\delta\left(\mathbf{H}_{\mathrm{OH}}\right)$ \\
\hline PAS & 6.09 & 6.09 & 7.42 & 5.96 & 11.41 \\
Zn(II) complex & 6.03 & 6.03 & 7.50 & 5.97 & \\
\hline
\end{tabular}




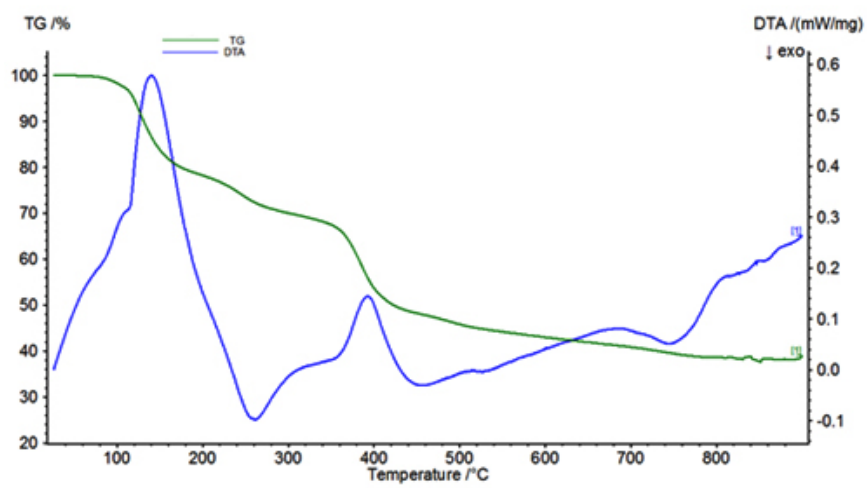

Fig. 4: TGA of Ni(II) complex of PAS<smiles>Nc1ccc2c(c1)OC(=O)c1ccc(N)cc1OCO2</smiles>

$\mathrm{M}=\mathrm{Mn}(\mathrm{II}), \mathrm{Fe}$ (II), $\mathrm{Co}(\mathrm{II}), \mathrm{Ni}(\mathrm{II}), \mathrm{Cu}$ (II) and $\mathrm{Zn}$ (II)

Fig. 5: Proposed structure of metal complexes of PAS

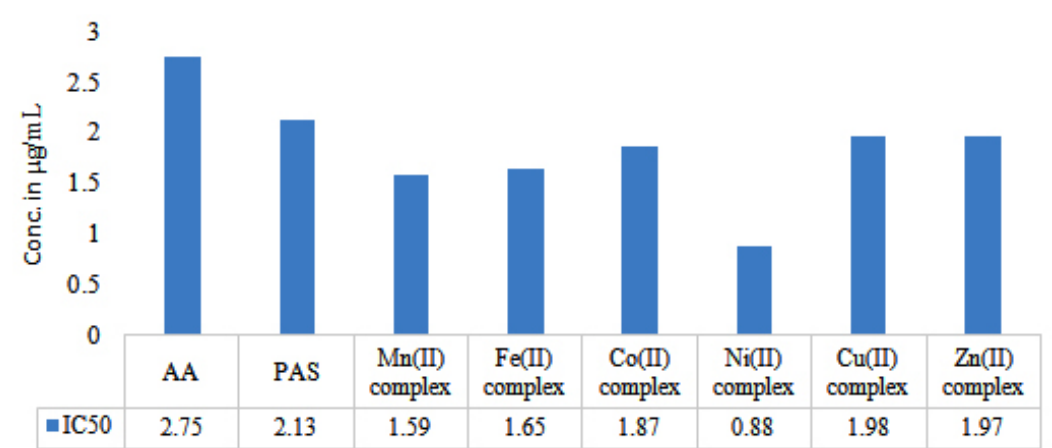

Fig. 6: $I_{50}$ values of PAS and its metal complexes compared with ascorbic acid

of phenoxyl radical formed with the help of metal ion in the intramolecular redox process and iii) of the attachment of functional end-group in order to control the solubility and transport of complexes. According to Li et al (2010) ${ }^{29}$, due to the chelation of organic moieties, metal complexes exhibit considerable radical scavenging. This view is also supported by Tyurin et al (2015) ${ }^{30}$ that antioxidant effect in metal complexes is observed due to the presence of an essential organic radical scavenger and redox-active metal.

The chemical, spectroscopic and thermal investigation of the complexes of PAS with transition metal ions viz.Mn(II), $\mathrm{Fe}(\mathrm{II}), \mathrm{Co}(\mathrm{II}), \mathrm{Ni}(\mathrm{II}), \mathrm{Cu}(\mathrm{II})$ and $\mathrm{Zn}$ (II) enabled us to determine the composition and suggest the surrounding environment of metals in these complexes.. The most important conclusion drawn from the above investigations is that the mono basic bi-dentate ligand is coordinated to the metal ions through Oxygen atoms of carboxylate and phenolic atoms. The DPPH assay in terms of $I C_{50}$ values indicates that the PAS and its metal complexes possess excellent antioxidant properties compared to Ascorbic acid, which is a potent reducing agent and scavenger of free radicals in biological systems and can therefore reduce oxidative stress. The study of these complexes can be an area of interest as these may affect the bio availability of PAS owing to their presence in relatively appreciable concentrations in biological fluids. 


\section{REFERENCES}

1. Seddon, J.A.; Hesseling, A.C.; Marais, B.J.; Mcllleron, H.; Peloquin, C.A.; Donald, P.R.; Schaaf, H.S. Tuberculosis. 2012, 92, 9-17.

2. Dhaneshwar, S.S. World J.fGastroenterol: WJG. 2014, 20, 3564.

3. Hartmman, A.P.; Jornada, D.H.; de Melo, E.B. Chem. Pap.2013, 67, 556-567.

4. Zhang, J.; Shan, Y.; Pan, X.; Wang, C.; Xu, W; He, L. Chem. Boil. Drug Des.2011, 78, 709-717.

5. Lehmann, J. Lancet. 1946, 15-16.

6. Zheng, J.; Rubin, E.J.; Bifani, P.; Mathys, V.; Lim, V.; Au, M.; Jang, J.; Nam, J.; Dick, T.; Walker, J.R.; Pethe, K. J Biol. Chem.2013, 288, 23447-23456.

7. Falzon, D.; Jaramillo, E.; Schünemann, H.J.; Arentz, M.; Bauer, M.; Bayona, J.; Blanc, L.; Caminero, J.A.; Daley, C.L.; Duncombe, C.; Fitzpatrick, C.. WHO guidelines for the programmatic management of drug-resistant tuberculosis: 2011 update.

8. Dinis, T.C.; Madeira, V.M.; Almeida, L.M. Arch. Biochem. Biophys. 1994, 315, 161-9.

9. Halliwell, B.;Gutteridge, J.M. Mol. Aspects Med. 1985, 8, 189-193.

10. Asanuma, M.; Miyazaki, I.; Ogawa, N. Curr. Pharm. Des.2004, 10, 695-700.

11. Wani, A.B.; Chadar, H.; Wani, A.H.; Singh, S.; Upadhyay, N. Environ. Chem. Lett.2016, 15,101-123.

12. Ky, S.Q.; Deng, H.S.; Xie, P.Y.; Hu, W. Br. J. Ind. Med. 1992, 49, 66-69.

13. Jiang, Y.M.; Mo, X.A.; Du, F.Q.; Fu, X.; Zhu, X.Y.; Gao, H.Y.; Xie, J.L.; Liao, F.L.; Pira, E.; Zheng, W. J. Occup. Environ. Med./Am. Coll. Occup. Environ. Med.2006, 48, 644.

14. Crabb, E.; Moore, E. Metals and Life Chapter 9. RSC Publishing. 2010. http://prospect.rsc. org/metalsandlife/

15. Johnston, A.E. 2005 15,7. http://www.lbhi.is/ sites/default/files/gogn/vidhengi/thjonusta/ utgefid_efni/ritlbhi/rit_lbhi_nr_3.pdf\#page=9

16. Sharma, O.P.; Bhat, T.K. Food Chem. 2009, 113, 1202-1205.

17. Duarte, T.L.; Lunec, J. Free Radic. Res. 2005, 39, 671-686.

18. Soliman, M.H.; Mohamed, G.G. Spectrochim. Acta A. Mol. Biomol. Spectros.2013, 107, 8-15.

19. El Anany, A.M. J. of Food Sci. Tech. 2015, 52, 2175-2183.

20. Gul, R.; Badshah, A.; Khan, A.; Junaid, A.; Rauf, M.K. Spectrochim. Acta. A Mol. Biomol. Spectrosc. 2014, 117, 264-269.

21. Salama, F.; El-Abasawy, N.; Razeq, S.A.; Ismail, M.M.F.; Fouad, M.M. J. Pharm. Biomed. Anal. 2003, 33, 411-421.

22. Hoshina, T.A.; Tsuchihashi, N.; Ibuki, K.; Ueno, M. The J. Chem. Phy. 2004, 120, 43554365.

23. Liu, H.; Wang, H.; Gao, F.; Niu, D.; Lu, Z. J. Coord. Chem.2007, 60, 2671-2678.

24. El-Sherif, A.A. Inorg. Chim. Acta.2009, 362, 4991-5000.

25. Varghese, H.T.; Panicker, C.Y.; Philip, D.; Mannekutla, J.R.; Inamdar, S.R. Spectrochim. Acta. A Mol. Biomol. Spectrosc. 2007, 66, 959-963.

26. Panicker, C.Y.; Varghese, H.T.; John, A.; Philip, D.; Istvan, K.; Keresztury, G. Spectrochim. Acta. A Mol. Biomol. Spectrosc.2002, 58, 281-287.

27. Hansen, P.E.; SpangetLarsen, J. Patai's Chemistry of Functional Groups. 2003.

28. R Milaeva, E. Curr. Top. Med. Chem. 2011, 11, 2703-2713.

29. Li, Y.; Yang, Z.Y.;Wang, M.F. J. Fluoresc. 2010, 20, 891-905.

30. Tyurin, V.Y.; Moiseeva, A.À.; Shpakovsky, D.B.; Milaeva, E.R. J. Electroanal. Chem. 2015, $756,212-221$. 